\author{
Sorry, for copyright \\ reasons some images \\ on this page may not \\ be available online
}

\author{
Sorry, for copyright \\ reasons some images \\ on this page may not \\ be available online
}

Traditional bullock carts: just right for local conditions. Modernising them could be beyond village craftsmen.

\title{
Beware of imported technology, says Indian group
}

TMPORTED technology benefits the rich 1 but not the poor, believes one group of scientists in India. This is ASTRA, the Cell for the Application of Science and Technology to Rural Areas, at the Indian Institute of Science (IIS) in Bangalore. And ASTRA is determined to provide alternatives.

A group at the Institute started the ball rolling four years ago with a series of seminars on rural problems. These were intended to get members in various departments to start practical projects on these problems. The underlying philosophy was that most imported technology will tend to benefit the urban population or the relatively rich villagers and may even worsen the lot of the rural poor. Given this, the group argued, developments are needed which require low capital investment and maintain or increase the level of employment. Since they have to be accepted by villagers developments must also operate within the framework of the Indian village.

The group formed itself into ASTRA. The first problem it faced was that the villages are already very developed systems with a rigid social structure and with virtually complete, if inefficient, usage of all the available resources except manpower. Any dramatic developments when introduced into this framework are likely to unbalance the whole society and work to the detriment of the poorest people. So ASTRA had to aim to work within the system producing a series of technical perturbations which can be absorbed into village life without any social upheaval. To promote this ASTRA has an extension centre in a village about $100 \mathrm{~km}$ from Bangalore, close enough that it is easy to visit but far enough that the academic visitors will have to spend the night there and so will be encouraged to see their work in its context.

One project which has attracted a lot of attention is a study of bullock carts. There are about 12 million of these single axle carts in India, worth about $£ 100$ each. ASTRA engineers have analysed the vertical and horizontal forces on the bullock as a function of wheel diameter, ground slope and friction. They concluded that the usual unsprung cart with large wooden wheels, is already excellent for the transport of light loads over rough grounds. ASTRA is studying the possible advantages of pneumatic tyres and ball bearings, though these have the disadvantage that they are beyond the scope of the traditional wheelwright. Measurements on carts mounted with load cells are being made to check the calculated results. Recently a shortage of teak needed to construct the wheels has lead to studies of other woods which might have the correct combination of mechanical properties and dimensional stability.

Another project illustrating the main themes of ASTRA concerns the use of a simple press to make mud blocks for house walls at lower cost than blocks or bricks made by hand. An analysis has been made of stress distributions in a mud-walled house and of the strength properties of the blocks. The major problem with mud walls is weather resistance and studies are being made of improvements with small additions of cement. Using this system a single storey laboratory has been built to house a project on methane production from waste.

Many people feel that India should be endeavouring to eliminate bullock carts rather than to improve them and thus consider ASTRA's efforts to be misguided. It is also tempting to think that rural life needs major social changes rather than minor technological ones but so far the village has proved to be a very stable, conservative society. Since ASTRA's approach is relatively cheap and the adverse con- sequences of their innovations should be minor, they really only have to prove that they can produce effective changes. This means producing modifications to existing methods which are within their guidelines of being labour-intensive, fuel-saving, and acceptable to the villagers. An ASTRA report on an exhibition of low cost houses designed by various research groups makes the point very strongly that an acceptable result is unlikely unless close links are maintained with a rural area. Faults in these houses included use of industrial materials such as plywood, poor thermal insulation and designs which left no space for stabling animals under the same roof.

A further point which has to be proven is that such "alternative technology" research can be usefully housed within universities. ASTRA is essentially a loose grouping of faculty whose primary allegiance is to their academic departments. It is held together by a convenor, currently $\mathrm{Dr}$ Amulia K. N. Reddy, who must maintain a feeling of unity within the group and act as the representative for the group as a whole to the outside world. For such a group to hold together it is necessary that the research can be seen to involve application of advanced scientific and engineering methods on a par with those in other types of research. The examples given above involve aspects of civil and mechanical engineering and materials science and other projects clearly involve chemistry and chemical engineering. A demonstration that these projects do have strong roots in the pure sciences would go a long way towards supporting the idea that pure scientific research should be maintained in underdeveloped countries as a resource for applied research and to justifying European training in pure research of students from these countries.

Paul Calvert 